\title{
Entre o nacional e o internacional: o surgimento histórico da sociologia como campo*
}

Gisèle Sapiro**

Resumo: O trabalho centra a atenção no desenvolvimento histórico da sociologia enquanto campo passível de ser analisado com as ferramentas da sociologia histórica. Num primeiro momento, o trabalho destaca o processo histórico de nacionalização da pesquisa e da capacitação da sociologia, procurando transcender o nacionalismo metodológico, uma vez que estuda os acontecimentos nacionais como se ocorressem endogenamente, sem a interferência de fatores internacionais. Num segundo momento, o texto destaca o processo de internacionalização da sociologia, que se intensificou no período pós-guerra, quando se observou a existência de uma estrutura de relações de poder acadêmico existente entre as diferentes sociologias nacionais, em função de condições materiais e simbólicas existentes no âmbito dos diferentes países.

Palavras chaves: Institucionalização acadêmica. Profissionalização, autonomização do campo científico. Constituição de mercados editoriais nacionais e internacionais.

\section{Between national and international: the historical emergence of sociology as a field}

Abstract: Abstract: The paper focuses attention on the historical development of sociology as a field that can be analyzed using the tools of historical sociology. First, the work highlights the historical process of nationalization of research and training in sociology, in an attempt to transcend methodological nationalism. This is accomplished by studying national events as if they occurred endogenously, without the interference of international factors. Next, the text highlights the process of internationalization of sociology that intensified in the post-war period, in which the existence of a structure of academic power relations between the sociologies of different nations is seen, due to the material and symbolic conditions within the different countries.

Keywords: Academic institutionalization. Professionalization, empowerment of the scientific field. Constitution of national and international publishing markets.

A s histórias das disciplinas têm sido, em certa medida, transnacionais, com um enfoque nas figuras de seus pais fundadores. Na sociologia, estes incluem, às vezes, Marx, e sempre Comte, Durkheim e Weber. Entretanto, essas histórias são relatos teóricos incorpóreos que estudam o avanço das ideias como se elas estivessem circulando por conta própria. Pode parecer surpreendente que os sociólogos reproduzam esse tipo de história das ideias com um enfoque em

\author{
* Tradução: \\ Dermeval de Sena \\ Aires Júnior. \\ ** Gisèle Sapiro \\ é socióloga e \\ pesquisadora no \\ Centre National \\ de la Recherche \\ Scientifique (CNRS), \\ Paris, França; \\ vice-presidente \\ para assuntos \\ internacionais da \\ École des Hautes \\ Études en Sciences \\ Sociales (Ehess), \\ Paris, França. \\ <sapiro@ehess.fr>.
}


autores cujos nomes, propriamente ditos, não se referem tanto a indivíduos como servem de rótulos para o corpus de uma obra - o que Foucault (1994) denominou "função-autor". Essa prática se torna menos surpreendente se consideramos que a construção de referências do passado e de uma história específica da consolidação de uma disciplina é típica do que Bourdieu (1980b, 2013) define como um "campo". Os campos são espaços relativamente autônomos definidos pelas regras específicas do jogo e por um tipo específico de capital. Os atores no campo lutam a fim de ganhar o capital específico e impor a sua definição da atividade do campo. Essas disputas são arbitradas por autoridades específicas, por exemplo, no nosso caso, os periódicos científicos, determinadas premiações, comitês de promoção e assim por diante. Os campos também são definidos pela referência à sua própria história.

Proponho-me aqui considerar a sociologia em seu desenvolvimento histórico como disciplina e como campo, passível de ser estudada com as ferramentas da sociologia histórica. A história sociológica das ciências sociais e humanas iniciou como um domínio de pesquisa (ver, por exemplo, Bourdieu, 1984; Collins, 1998; Abbott, 2001). As contribuições significativas recentes voltaram-se para a história sociológica da sociologia com enfoque em um contexto nacional específico (Calhoun, 2008; Fleck, 2016; Heilbron, 2015). Entretanto, é de se estranhar que a sociologia histórica das ciências humanas e sociais não tenha se desenvolvido como parte dos "estudos de ciência", o que deixou essas disciplinas fora de seu campo de pesquisa. Esse desenvolvimento paralelo se deve provavelmente ao fato de que a história das ciências humanas esteve relacionada, desde o início, à história intelectual e à sociologia dos intelectuais. Essa ligação também explica porque, à diferença da história transnacional das ideias, esta história continuou bastante nacional até a década de 1990. Neste caso, o "nacionalismo metodológico" (Wimmer \& Schiller, 2003) também é o resultado da organização nacional do ensino e da pesquisa de nível superior.

Uma sociologia histórica das disciplinas em geral - e da sociologia em particular deve lidar com o processo histórico de nacionalização da pesquisa e da capacitação, transcendendo sempre o nacionalismo metodológico. A crítica ao nacionalismo metodológico repreendeu os estudos comparatistas por reificarem as fronteiras nacionais e estudarem os acontecimentos nacionais como se ocorressem endogenamente, sem a interferência de fatores internacionais. É verdade que muitos países, ao se tornaram Estados nacionais, compartilharam uma cultura e uma herança comuns com alguns de seus vizinhos, a exemplo da comunidade acadêmica na Europa, que se comunicava em latim (Karady, 2009). Além disso, mesmo após a consolidação dos Estados nacionais, o intercâmbio e a circulação (de pessoas, bens e modelos) não cessaram (Heilbron, Jeanpierre \& Guilhot, 2009). O colonialismo também fomentou a circulação de pessoas, bens e conhecimento (Steinmetz, 2007). 
A fim de relatar e compreender esse intercâmbio e essa circulação, os historiadores propuseram as noções de "história enredada" (entangled history), "história conectada" (connected history) ou "história cruzada" (histoire croisée) (a respeito desta última, ver Werner \& Zimmerman, 2006). Essas abordagens têm sido bastante frutíferas desde meados dos anos 1990, contudo, deixam frequentemente de levar em conta as relações de poder entre as culturas. Essas relações de poder estão no centro da teoria do sistema-mundo desenvolvida após Braudel, na América Latina, no âmbito da Teoria da Dependência, e elaborada de forma diferente por Immanuel Wallerstein (2004). A teoria do sistema-mundo é uma abordagem global que considera a constelação de relações de poder e a desigual distribuição dos bens e do capital entre todas as sociedades no mundo. A teoria do sistema-mundo tem sido utilizada para analisar o sistema da língua global (De Swaan, 2001) e o sistema mundial de traduções. Ela tem sido útil para repensar a teoria do campo em escala global e articular o caráter comparativo e as transferências existentes, considerando também as relações de poder entre culturas (ver Casanova, 1999, para a República mundial das letras; Sapiro, 2016, acerca do mercado mundial de tradução; e, para um arcabouço teórico mais amplo acerca dos campos transnacionais, ver Sapiro, 2013a).

Quero sugerir uma abordagem semelhante para repensar a sociologia histórica das disciplinas e, em particular, da sociologia a partir de uma perspectiva transnacional. Proponho, em primeiro lugar, a identificação de quatro processos frequentemente relacionados, porém distintos, que devem ser diferenciados entre si: a institucionalização acadêmica, a profissionalização, a autonomização de um campo científico e a ascensão do mercado editorial. Esses processos estão embutidos na divisão nacional e internacional do trabalho científico e nas relações de poder dentro do sistema de disciplinas. Na segunda parte do artigo, discutirei processos de nacionalização, internacionalização e transnacionalização, destacando também duas fases do processo de institucionalização das ciências sociais e das humanidades: da segunda metade do século XIX à década de 1930; e da década de 1950 à década de 1970 - o período visto como a idade de ouro da ciência social ${ }^{1}$.

\section{Institucionalização, profissionalização e autonomização}

A institucionalização é entendida aqui como o desenvolvimento institucional das disciplinas dentro do sistema acadêmico, com a criação de currículos, de postos de trabalho com ensino e diplomas. A própria noção de disciplina está historicamente relacionada à universidade, e não à ciência (Stichweh, 1992). Os estudos jurídicos se relacionam a um conjunto de conhecimentos transmitidos no âmbito da acade-
1. Este programa de pesquisa baseia-se amplamente no trabalho realizado pelo projeto europeu Cooperação Internacional de Ciências Sociais e Humanidades (Interco-SSH), coordenado por mim entre 2013 e 2017, a partir do Acordo de Financiamento $\mathrm{n}$. 319974. Ver <http:// interco-ssh.eu/en> 
mia, que não depende de um campo científico específico. Esses conhecimentos têm como enfoque principal a capacitação de profissionais, enquanto que a pesquisa se torna uma parte bastante pequena de sua disciplina. Nas ciências sociais e humanas, a filosofia, os estudos literários e a história foram institucionalizados como disciplinas acadêmicas voltadas à capacitação de professores secundaristas, antes da pesquisa ter se desenvolvido nessas áreas. Como ressalta Andew Abbott (2001), as disciplinas formam um sistema, uma "ecologia", e precisam definir suas fronteiras em relação umas às outras. Por exemplo, a sociologia surgiu em alguns países nas faculdades de direito (Países Baixos ou Brasil), enquanto, na França, surgiu no departamento de filosofia.

No projeto Cooperação Internacional de Ciências Sociais e Humanidades (Interco-SSH), pudemos construir indicadores de institucionalização, como a criação de cátedras e departamentos, a criação de atividades de capacitação de graduação e pós-graduação, e o número de doutoramentos (Fleck, Heilbron, Karady \& Sapiro, 2016). A primeira cátedra de sociologia foi criada em Chicago, por Albion Small, para formar assistentes sociais, e no início do século XX, a disciplina já estava bem estabelecida nos Estados Unidos, com 55 professores trabalhando em regime de jornada integral em 1909, e 372 professores em regime parcial (Bernard 1909: 186). Na França, a primeira cátedra de sociologia foi fundada em 1913, por Durkheim. Na Alemanha, quatro cátedras foram estabelecidas em 1919. Ao final da República de Weimar, havia cerca de 50 professores de sociologia trabalhando em tempo integral ou parcial na Alemanha, e um total de 140 sociólogos, enquanto nos Estados Unidos, já existiam mil professores universitários de sociologia (Käsler, 2013; Lepsius, 1983; Fleck, 2011). No Brasil, a sociologia foi ensinada na educação secundarista e nas escolas normais antes de se estabelecer como disciplina acadêmica, na década de 1930. Na Itália, as primeiras cátedras de sociologia surgiram apenas após a Segunda Guerra Mundial: a primeira delas foi criada em 1959, na Faculdade de Direito da Universidade de Roma, La Sapienza.

O oposto desse processo - isto é, a desinstitucionalização - pode ser visto em contextos de profundas transformações sociais ou aumento do controle político, tal como ocorreu na Alemanha nazista (Ramstedt, 1986), na França do autoritário regime de Vichy, que suprimiu a sociologia (Muel-Dreyfus 2004), nos regimes comunistas, ou sob as ditaduras sul-americanas. Porém, os regimes autoritários também podem favorecer o desenvolvimento de determinadas disciplinas das ciências sociais, como a estatística, no contexto da Itália fascista (Prévost, 2009) ou da União Soviética (Blum, 2004). A desinstitucionalização também pode resultar de uma reconfiguração da divisão do trabalho acadêmico após o surgimento de novas disciplinas. A profissionalização - ou, segundo Andrew Abbott (1989), o desenvolvimento pro- 
fissional - caracteriza-se pelo advento de organizações profissionais como as associações, que defendem os interesses da profissão, mas também desempenham um papel regulador para a definição de uma ética profissional. Esse processo não está necessariamente relacionado à institucionalização acadêmica, como mostra o caso da psicanálise, mas, atualmente, a maioria das profissões intelectuais requer uma formação acadêmica.

A sociologia foi institucionalizada pela primeira vez nos Estados Unidos para formar assistentes sociais, mas a assistência social, em um determinado momento, foi excluída da disciplina, à medida que se organizou como profissão. Sua primeira organização foi criada em 1905. Na França, a sociologia não se desenvolveu como profissão fora da academia, com a exceção do ensino secundário, a partir de 1977. A organização profissional aconteceu tardiamente (a associação foi criada em 2001), posto que a sociologia era mais marcadamente um campo científico dividido entre escolas concorrentes e heterogênea em seu recrutamento e em sua formação social.

Pode-se observar que o modelo organizacional que prevaleceu até a Segunda Guerra Mundial foi um modelo de sociedades eruditas baseadas em cooptação e menos preocupadas com questões profissionais do que com o intercâmbio científico, movendo-se após a guerra em direção a associações com base na participação voluntária e em reuniões que tratavam de questões tanto científicas como profissionais, seguindo o modelo da Associação Sociológica Internacional, criada em 1949. A Sociedade Sociológica Americana, por exemplo, tornou-se uma associação em 1959 (a este respeito, ver exemplos não exaustivos no Quadro 1). Aqui, o modelo nacional parece seguir o modelo internacional. Voltarei a este ponto adiante.

Um processo inverso - de desprofissionalização - também pode ser visto em regimes políticos como o nazista na Alemanha, mas tais contextos também podem favorecer o desenvolvimento profissional conduzidos pelo Estado, assim como ocorreu na União Soviética. A desprofissionalização pode também resultar de disputas e divisões dentro de um grupo profissional, levando a alianças com outras disciplinas.

O desenvolvimento científico pode ser observado com o surgimento do que Thomas Kuhn (1970) denomina "matriz disciplinar" (isto é, generalizações simbólicas - a crença compartilhada na validade de determinadas afirmações -, valores compartiIhados, e exemplos compartilhados de soluções para determinados problemas), e, usando o conceito de Bourdieu, da autonomização de um campo científico (Bourdieu, 1980b). Um campo científico, como já mencionado, é definido por problemas e ferramentas específicas, e por uma concorrência singular regrada por autoridades 


\section{QUADRO 1}

SOCIEDADES ERUDITAS VERSUS ASSOCIAÇÕES

\begin{tabular}{|c|}
\hline 1895 Société de Sociologie de Paris \\
\hline 1903 Sociological Society (UK) \\
\hline 1905 American Sociological Society \\
\hline 1909 Deutsche Gesellschaft für Soziologie \\
\hline 1936 Dutch Sociological Society (NSV) \\
\hline 1937 Sociedade Brasileira de Sociologia \\
\hline 1949 Associação Sociológica Internacional (ISA) \\
\hline 1950 Asociación Latinoamericana de Sociología (Alas) \\
\hline 1950 Indian Sociological Society (ISS) \\
\hline 1951 British Sociological Association (BSA) \\
\hline 1958 Association des Sociologues de Langue Française (ASLF) \\
\hline 1959 American Sociological Association (ASS renamed) \\
\hline 1963 Société Française de Sociologie (SFS) \\
\hline 1967 Israeli Sociological Society \\
\hline 1979 Chinese Sociological Association (CSA) \\
\hline 1983 Associazione Italiana di Sociologia (AIS) \\
\hline 1983 Hungarian Sociological Association \\
\hline 1992 Associação Sociológica Europeia (ESA) \\
\hline 2000 Asociación de Sociólogos de la República Argentina (Asra) \\
\hline 2001 Association Française de Sociologie (AFS) \\
\hline
\end{tabular}

também específicas, como as revistas científicas (o Quadro 2 traz exemplos de periódicos sociológicos lançados nas duas fases de institucionalização). A autonomia é aqui definida como certo grau de independência da ideologia, do Estado ou das demandas econômicas por capacidades aplicáveis. Estas últimas estão relacionadas com a distinção entre ciências puras e aplicadas (como a sociologia eleitoral, ou parte da sociologia das organizações), ainda que tal distinção deva comportar algumas gradações: por exemplo, uma pesquisa encomendada a uma área do conhecimento especializado ainda pode ser relativamente autônoma.

As novas áreas de especialização surgem ou como resultado de processos de diferenciação, ou como o que Andrew Abbott denomina de "fracionamento" (tomando seu modelo emprestado da física); ou, ainda, por uma "hibridização", no sentido de uma importação de métodos, problemas e ferramentas conceituais de outras disciplinas ou áreas de especialização, assim como Collins e Ben-David (1966) sugeriram, a partir de estudo de caso de psicologia experimental no século XIX. 


\section{QUADRO 2}

EXEMPLOS DE LANÇAMENTO DE PERIÓDICOS SOCIOLÓGICOS

\begin{tabular}{|c|}
\hline 1893 Revue Internationale de Sociologie \\
\hline 1894-1896 Rivista di Sociologia \\
\hline 1896 L'Année Sociologique \\
\hline 1897 Rivista Italiana di Sociologia \\
\hline 1908 The Sociological Review \\
\hline 1921-1934 Kölner Vierteljahreshefte für Soziologie \\
\hline 1925 Mens(ch) en Maatschappij (NL) \\
\hline 1936 American Sociological Review \\
\hline 1939 Revista Mexicana de Sociología \\
\hline 1946 Cahiers Internationaux de Sociologie \\
\hline 1948 Kölner Zeitschrift für Soziologie und Sozialpsychologie \\
\hline 1949 L'Année Sociologique (relançamento) \\
\hline 1950 British Journal of Sociology \\
\hline 1951 Quaderni di Sociologia (IT) \\
\hline 1953 Sociologische Gids (NL) \\
\hline 1956 Archives de Sociologie des Religions \\
\hline 1956 Sociologia: Bollettino dell'Istituto Luigi Sturzo \\
\hline 1959 Sociologie du Travail \\
\hline 1960 Revue Française de Sociologie \\
\hline 1960 Archives Européennes de Sociologie \\
\hline 1960 Rassegna Italiana di Sociologia \\
\hline 1963 Studi di Sociologia \\
\hline 1967 La Critica Sociologica \\
\hline 1967 Sociology \\
\hline 1975 Actes de la Recherche en Sciences Sociales \\
\hline
\end{tabular}

A psicologia e a sociologia se desenvolveram primeiramente na França como ciências antes de serem submetidas à institucionalização acadêmica. No campo sociológico francês, ocorreu uma disputa específica entre a escola de Durkheim, denominada de Escola Francesa de Sociologia, que editava o periódico L'Année Sociologique, desde 1898; a pesquisa empírica em torno de Le Play, que editava La Réforme Sociale; e o grupo em volta de René Worms, que, em 1904, lançou a Revue Internationale de Sociologie. Nenhum dos três detinha então uma cátedra em sociologia. Worms e Le Play sequer eram professores universitários. Durkheim teve formação de filósofo e foi indicado a uma cátedra na Sorbonne, em 1906, de ciências da educação. Em 1913, mudou o nome da cátedra para sociologia e fez, 
desse modo, com que ela se tornasse a primeira cátedra de sociologia da França. Em 1924, os durkheimianos fundaram uma sociedade de eruditos, o Institut Français de Sociologie, que desempenhou um papel na perpetuação do prestígio científico da disciplina (Karady, 1976; Heilbron, 2015; Joly, 2017). Vale notar que enquanto Durkheim trabalhou com afinco para estabelecer a sociologia como ciência sui generis, distinta da biologia e da psicologia, suas fronteiras com a etnologia - que ainda não estava institucionalizada na academia - eram permeáveis. Essa trajetória evolutiva, partindo de um campo em direção a uma disciplina, contrasta com o caso dos Estados Unidos, onde a sociologia foi primeiramente institucionalizada como disciplina acadêmica com orientação vocacional específica, para formar assistentes sociais. O caso alemão, por sua vez, assemelha-se mais ao francês (Käsler, 2013; Joly, 2017).

O processo oposto à autonomização dos campos é a perda da autonomia, que ocorre em regimes autoritários, mas também em situações de restrições econômicas exacerbadas. A heteronomia ideológica pode ser ilustrada pelo exemplo do sociólogo alemão Richard Thurnwald, que se tornou o teórico do império da Alemanha nazista (Steinmetz, 2010).

As demandas políticas ou econômicas contribuíram ao desenvolvimento das ciências sociais em diversos países, incluindo a França, onde a pesquisa é financiada principalmente pelo Estado. Algumas disciplinas - como a etnologia - claramente se desenvolveram em resposta à demanda dos Estados coloniais, na França e na Alemanha: um instituto colonial foi fundado em Hamburgo, em 1907. Da mesma forma, o Institut d'Ethnologie de l'Université de Paris, fundado em 1925 pelo Ministério das Colônias, propôs um curso de graduação em estudos de etnologia colonial para formar servidores públicos civis e produzir conhecimentos a respeito das colônias onde eles estavam lotados. O sucesso da antropologia estrutural de Lévi-Straus se deve parcialmente ao fato de que, valendo-se da antropologia e da linguística norte-americanas, ofertou à etnologia uma teoria universal, possibilitando dar um passo à frente do contexto colonial no qual ela estava integrada na França para tornar-se um campo de conhecimento autônomo.

Porém, o Estado pode conceder certo grau de autonomia ao campo acadêmico. Assim ocorreu na França, onde os acadêmicos se beneficiam de um status especial na condição de servidores públicos, uma vez que o seu trabalho é avaliado entre pares, e não por superiores. O financiamento estatal pode proteger a pesquisa contra demandas econômicas de grandes empresas, que criaram obstáculos heterônomos. Fundações filantrópicas também prestaram apoio a pesquisadores exilados na América do Norte e do Sul (Fleck, 2011). 
Outro importante fator de desenvolvimento das ciências sociais e humanas é a ascensão de um mercado editorial especializado. O interesse das editoras em obras acadêmicas surgiu na primeira metade do século $X X$, em estreita relação com o desenvolvimento da educação superior. As universidades criaram editoras acadêmicas, seguindo o modelo de Oxford e Cambridge, no Reino Unido. A editora universitária de Princeton foi fundada em 1905; a de Yale, em 1908, e a de Harvard, em 1913. Na França, assim como na Alemanha e na Itália, pequenas editoras acadêmicas (Alcan, Vrin e Payot) surgiram no período entreguerras e criaram um mercado especializado (Fabiani, 1988; Tesnières, 2001). Na década de 1950, grandes editoras comerciais se tornaram cada vez mais interessadas nas ciências sociais e humanas na França, na Itália (Feltrinelli, Bompiani que publicou Umberto Eco) e na Alemanha (Hanser, Suhrkamp, Wagenbach). Assim, nos anos 1930 e 1940, a Gallimard - a mais prestigiada editora francesa - começou a traduzir as obras de Freud e a publicar Sartre e Merleau-Ponty, e lançou em 1950 a "Bibliothèque de la Philosophie". Algumas séries das recém-denominadas "ciências humanas" foram publicadas por outras editoras nos anos 1960, organizadas por figuras carismáticas como de Dampierre ("Recherches en Sciences Humaines", Plon, 1950), Lacan ("Le Champ Freudien”, Les Éditions du Seuil, 1964), Bourdieu ("Le Sens Commun", Minuit, 1966), Nora ("Bibliothèque des Sciences Humaines", Gallimard, 1966), e Todorov e Genette ("Poétique", Les Éditions du Seuil, 1970), que contavam com um público do mundo acadêmico. Uma pequena editora engajada como a Maspero pôde publicar ciências sociais críticas terceiro-mundistas (Joseph 2010). Por sua vez, nos Estados Unidos, a Pantheon Books traduziu obras de Sartre e Foucault.

Esses processos convergiram em duas fases de institucionalização das ciências sociais e humanas no mundo ocidental. A convergência desses processos é, em certa medida, fruto de políticas de Estado com vistas a desenvolver a pesquisa científica dentro das universidades, seguindo o modelo da Universidade de Humboldt. $\mathrm{Na}$ França, esse processo foi iniciado com a criação da Nouvelle Sorbonne, em 1896, sob a Terceira República, atingindo a plenitude na década de 1960. Tal convergência criou o que Bourdieu (1984) chamou de campo acadêmico, incluindo tanto as universidades como as instituições de pesquisa. Após a Segunda Guerra Mundial, essa convergência verificou-se também em decorrência da introdução na academia do modelo anglo-americano de organização profissional e do modelo científico de pesquisa empírica imposto por intermédio de fundações filantrópicas, bem como ao surgimento de um mercado editorial específico para o crescente público de acadêmicos e estudantes. Se a primeira fase dessa institucionalização foi marcada principalmente pela nacionalização e pelo colonialismo, a segunda ocorreu como configuração mais transnacional e caracterizou-se pelo desenvolvimento profissional e pelo planejamento que estruturou a demanda por parte das ciências sociais. 


\section{Nacionalização,}

internacionalização, transnacionalização

A "República das Letras" na Europa do século XVIII era uma comunidade bastante unificada. Unificada por uma língua - o latim - e pela unidade do conhecimento. A divisão do trabalho científico e a construção dos Estados nacionais levaram à fragmentação do campo intelectual europeu, enquanto o colonialismo contribuiu ao alastramento desse conhecimento por todo o mundo, quando ele se deparou com outras tradições de conhecimento culto. A construção dos Estados nacionais e o colonialismo geraram uma demanda específica pelo conhecimento científico.

Assim como a profissionalização, também a nacionalização da educação superior e das instituições de pesquisa foi parte de um processo mais amplo que influenciou outros campos, como a literatura, a pintura e a música durante os séculos XIX e XX (Sapiro, 2013a). A construção cultural das identidades nacionais aconteceu em meio a uma acirrada competição entre os Estados nacionais (Thiesse, 1998), e à disseminação do modelo da Universidade de Humboldt, que combinava ensino e pesquisa. Assim, esse processo de nacionalização foi internacional em sua essência, e a concorrência alimentou o isomorfismo organizacional na academia. Segundo a análise neoinstitucionalista, o isomorfismo organizacional é resultado ou de restrições, ou de normas profissionais, ou da concorrência (Di Maggio \& Powell, 1983). No mundo acadêmico ocidental, a concorrência promoveu, em primeiro lugar, a circulação internacional do modelo organizacional por meio da imitação, antes que normas profissionais fossem promovidas por organizações internacionais, como veremos adiante. Entretanto, para entendermos a lógica subjacente a essa imitação, precisamos considerar o capital simbólico (Bourdieu 1980b: 191208; Sapiro, 2016).

Como já foi dito, a reforma francesa que criou a universidade republicana em 1896 foi modelada seguindo a Universidade de Humboldt, com base na crença de que a derrota sofrida pela França nas mãos dos prussianos na guerra de 1870 foi resultado de um desenvolvimento insuficiente na educação das elites. Durkheim e outros estudiosos foram enviados à Alemanha para aprender mais a respeito desse modelo (Charle, 1996). Enquanto os franceses dominavam o campo literário transnacional, os alemães predominaram o campo global da ciência, até a Segunda Guerra Mundial. A filosofia alemã concentrava a dimensão mais elevada de capital simbólico. Filósofos como Sartre e Aron viajaram para a Alemanha, no início da década de 1930 (Aron chegou até mesmo a presenciar a queima de livros por estudantes perto da universidade, em 1933). O prestígio da filosofia alemã não diminuiu nem mesmo após a guerra. O fato de que Heidegger continuou sendo estudado e admirado após 
a revelação do seu envolvimento com os nazistas, o que gerou uma ampla controvérsia no campo intelectual francês nos anos 1970, atesta a inércia do capital simbólico: apesar dessa revelação, a Gallimard publicou as obras completas de Heidegger traduzidas, na década de 1980.

A hegemonia das tradições nacionais varia entre as distintas disciplinas. Na sociologia, as tradições alemã e francesa predominaram até a década de 1960. De acordo com o N-Gram Viewer, Auguste Comte foi, após Karl Marx, o segundo sociólogo mais citado em inglês até meados dos anos 1930, quando Max Weber o ultrapassou na segunda colocação. Comte continuou a ser uma referência contínua até meados dos anos 1960. Max Weber foi introduzido nos Estados Unidos por Talcott Parsons, que descobriu sua obra enquanto fazia seu doutorado em Heidelberg, na década de 1920, e traduziu algumas de suas contribuições. Parsons, que foi um dos primeiros orientadores do então recém-criado departamento de sociologia de Harvard, também contribuiu para firmar a presença de Durkheim - cuja obra havia sido introduzida nos Estados Unidos desde o final do século XIX - como referência canônica na sociologia norte-americana (Platt, 2003). Durkheim é uma referência central na Estrutura da ação social de Parsons, publicada em 1937, pouco antes da publicação da tradução de As regras do método sociológico em inglês. Após a guerra, as traduções das obras de Durkheim foram reimpressas e seu centenário foi comemorado em 1959. Na década de 1960, 89\% dos textos introdutórios à disciplina mencionaram Durkheim, e uma torrente de monografias e artigos foi dedicada ao seu pensamento. Durkheim despontou como um dos membros da "santíssima trindade" e era, em 1970, a segunda referência sociológica mais relevante em língua inglesa, após Weber. Hoje, a sociologia norte-americana tornou-se dominante no campo sociológico transnacional.

A obra de Durkheim também foi introduzida desde o final do século XIX em outros países, como o Brasil, onde a sociologia foi ensinada a partir da década de 1920 nas escolas normais, tal como na França. Em sua obra Princípios de sociologia (1935), Fernando de Azevedo, que ocupou a primeira cátedra de sociologia na Universidade de São Paulo e fundou a Sociedade Brasileira de Sociologia (SBS), estabeleceu Durkheim como referência canônica (junto com Simmel e Pareto) e publicou a primeira tradução para o português de As regras do método sociológico em sua série inaugurada em 1937, antes mesmo das primeiras traduções dessa obra em inglês (1938), japonês (1942), alemão (1961) e italiano (1963).

Juntamente com o processo de nacionalização descrito na primeira parte deste artigo, um movimento em direção à internacionalização se iniciou ao final do século XIX e continuou a desenvolver-se durante o período entreguerras, promovido pelo Ins- 
tituto Internacional de Cooperação Intelectual da Liga das Nações. Esse movimento foi muito diferente da República das Letras na Europa do século XVIII; baseava-se no reconhecimento das culturas nacionais, e assim acompanhava, ao invés de contrabalançar, o processo de nacionalização: como vimos, foram fundadas sociedades nacionais de eruditos em diversos países.

Apesar disso, pode-se observar que enquanto a organização da educação superior e as organizações profissionais de acadêmicos estavam sendo nacionalizadas, conforme o atestam os nomes dessas organizações (americana, britânica, alemã, holandesa, brasileira), o mesmo não aconteceu com os campos científicos antes da Segunda Guerra Mundial. Com exceção da Rivista Italiana di Sociologia, lançada em 1897, os nomes dos periódicos não faziam, na maioria dos casos, referência a uma nacionalidade. E o primeiro dos periódicos sociológicos, lançado em 1893 por René Worms, recebeu o título de Revue Internationale de Sociologie, atestando assim sua aspiração a um alcance e a uma perspectiva internacionais. A afirmação da identidade nacional nos títulos dos periódicos parece ter começado na década de 1930, com a American Sociological Review (1936) e a Revista Mexicana de Sociología (1939). A nacionalização da pesquisa científica acelerou-se no período pós-guerra, como o mostram os nomes dos periódicos: British Journal of Sociology (1951); Revue Française de Sociologie (1960); Rassegna Italiana di Sociologia (1960) (entretanto, o Kölner Zeitschrift für Soziologie und Sozialpsychologie, fundado em 1948, manteve em seu título o nome da cidade onde é publicado, Colônia, permanecendo alinhado ao seu predecessor, o Kölner Vierteljahreshefte für Soziologie, publicado entre 1921 e 1934).

Depois da Segunda Guerra Mundial, a circulação de ideias, modelos, financiamento e estudiosos também se acelerou sob a nova hegemonia norte-americana. Essa hegemonia foi exercida por intermédio de fundações filantrópicas e pela Organização das Nações Unidas para a Educação, a Ciência e a Cultura (Unesco), que recriou o Instituto Internacional de Cooperação Intelectual da Liga das Nações, sob a liderança dos Estados Unidos. Instigadas pela recém-nascida Unesco, surgiram novas associações internacionais: a União Internacional de Ciências Antropológicas e Etnológicas (Iuaes), em 1948; a Associação Sociológica Internacional (ISA) e a Associação Internacional de Ciência Política (Ipsa), em 1949; bem como a Associação Econômica Internacional (IEA) e a União Internacional de Ciência Psicológica (IUPsyS), em 1950.

Essas associações promoveram o desenvolvimento profissional de suas disciplinas, como já vimos em relação ao caso da sociologia (acerca das relações entre a BSA e a ISA, ver Platt, 2003): a maioria das sociedades eruditas nacionais anteriores adotou o modelo associativo, à diferença dos regimes autoritários (na Espanha e nos países 
latino-americanos) e comunistas (no leste europeu e na China), onde a sociologia foi subordinada à ideologia então vigente. A Unesco também promoveu a criação de departamentos de ciência política em todo o mundo como meio de pacificar as relações entre os países (Boncourt, 2011). Podemos falar aqui - e citando Di Maggio e Powell (1983), mais uma vez - de um isomorfismo institucional, baseado, neste caso, na difusão internacional de normas profissionais (ao invés de basear-se na concorrência, como aconteceu no caso da institucionalização acadêmica). Juntamente com as associações internacionais, também foram criadas associações regionais como a Asociación Latinoamericana de Sociología (Alas) na América Latina (1950) e muitas associações europeias a partir da segunda metade dos anos 1960 (a Associação Sociológica Europeia foi fundada mais adiante, em 1992; acerca das associações europeias, ver Boncourt 2016; 2017).

Enquanto a sociologia nos Estados Unidos foi renovada por acadêmicos imigrantes europeus que fugiram do nazismo e do regime francês de Vichy (Fleck, 2011, Jeanpierre, 2004; Loyer, 2005), a institucionalização da sociologia após a guerra na Europa claramente resultou da hegemonia dos Estados Unidos, e a reflete. As fundações filantrópicas promoveram nas ciências sociais um modelo de pesquisa empírica, especialmente quantitativa, seguindo o paradigma científico da ciência natural. O paradigma científico já havia sido reintroduzido nas ciências humanas e sociais no final do século XIX pela noção do positivismo desenvolvido por Auguste Comte, e foi intensamente discutido na Alemanha, onde Dilthey e Rickert cunharam as noções de Geisteswissencshaften e Kulturwissenschaften (humanidades e estudos culturais) a fim de propor um método alternativo baseado na hermenêutica (Habermas, 1987). Porém, enquanto os etnólogos realizaram algum trabalho de campo em suas expedições, os sociólogos nas universidades eram primariamente estudiosos teóricos que baseavam suas pesquisas em uma literatura de fontes secundárias. A promoção de uma ciência social empírica pelas fundações filantrópicas não era politicamente neutra: foi uma maneira de combater o marxismo, que estava ganhando autoridade nessas ciências (Pollak, 1976). Essas fundações filantrópicas também financiaram cientistas sociais exilados pelas ditaduras sul-americanas e organizações nesses mesmos países, a exemplo do Centro de Estudos de Direito Econômico e Social (Cedes) e do Instituto Di Tella na Argentina; do Centro Brasileiro de Análise e Planejamento (Cebrap), do Instituto de Desenvolvimento Social do Planalto (Idesp) e do Centro de Estudos e Cultura Contemporânea (Cedec) no Brasil; do Corporación de Estudios para Latinoamérica (Cieplan) no Chile; e do Instituto de Estudios Peruanos (IEP) no Peru (no caso do Brasil, ver Garcia, 2004).

Na Itália, os pensadores italianos do pós-guerra foram desconsiderados e substituídos pelo funcionalismo parsoniano e pelo modelo de pesquisa empírica. Por 
sua vez, na França, houve conflitos entre os proponentes desse modelo empírico e os defensores da sociologia histórica - dentre os quais, Raymond Aron -, que lançaram um periódico de sociologia histórica comparada intitulado Archives Européennes de Sociologie. Desde o século XIX, a sociologia europeia oscilou entre a abordagem universal e a histórica. Na Alemanha, esta tendência histórica se tornou dominante nos anos 1920. Todos os sociólogos históricos tiveram de deixar a Alemanha em 1933 e emigraram para os Estados Unidos, mas eram uma minoria e essa subdisciplina só alcançou o seu reconhecimento como tal na década de 1970 (a respeito da sociologia francesa no período pós-guerra, ver Heilbron, 2015; acerca da sociologia histórica, ver Steinmetz, 2007).

A separação entre teoria e pesquisa empírica coincidiu em muitos lugares com a divisão do trabalho entre instituições acadêmicas e de pesquisa (como o CNRS francês), que se desenvolveram em nível nacional durante essa segunda fase graças ao financiamento público. Na França, essa oposição foi ofuscada por Bourdieu e não estrutura mais o campo sociológico francês; mas ela ainda existe em muitos países. A oposição entre a teoria e a pesquisa empírica também coincidiu parcialmente com a oposição entre o nacional e o internacional, que Bourdieu (1984) identificou, para o caso francês, no Homo academicus: enquanto o polo acadêmico estava voltado para a reprodução do conhecimento em escala nacional, o polo da pesquisa (especialmente as pesquisas financiadas por fundações filantrópicas) dedicava-se à produção e ao reconhecimento internacional. Aqui, teoria correspondia a comentários acerca dos autores teóricos em relação ao ensino.

A demanda pública e privada também favoreceu a segunda fase da institucionalização das ciências sociais e, mais especificamente, da sociologia durante esse período. A demanda pública estava intensamente relacionada ao planejamento e contribuiu para a nacionalização da pesquisa. Por exemplo, na França, um Comitê Organizador de Pesquisas Aplicadas sobre o Desenvolvimento Econômico e Social (Cordes) foi fundado em 1969; aproximadamente a metade dos projetos financiados era de sociologia (Houdeville, 2007). Em paralelo à demanda pública, uma demanda privada por modelos organizacionais foi direcionada pelas empresas à psicologia e à sociologia - sociologia das organizações (para o caso francês, ver Henry, 2012).

Assim, durante essa segunda fase, marcada pela recém-estabelecida hegemonia norte-americana, observa-se uma convergência entre os quatro processos que estavam parcialmente desconectados na primeira fase: a autonomização científica, a institucionalização acadêmica, a profissionalização e o aparecimento do mercado editorial. Essa segunda fase também foi marcada pela internacionalização. 
Como observou o sociólogo da ciência franco-canadense Yves Gingras (2002), o grau de internacionalização das disciplinas é variável: o direito é a menos internacionalizada das disciplinas, enquanto a economia e a filosofia são bastante internacionais, ainda que haja subdisciplinas como o direito comparado e a literatura comparada, que, por sua vez, são mais internacionais do que o núcleo duro de suas disciplinas. A internacionalização pode ser medida por meio de diferentes variáveis, como as associações internacionais, os periódicos internacionais e o compartilhamento de referências estrangeiras em citações, publicações em outros idiomas ou traduções (Heilbron et alii, 2017b).

Tomemos, neste ponto, a tradução de livros acadêmicos como indicador de padrões de internacionalização do campo das ciências humanas e sociais, e da circulação de ideias nos países. É claro, a publicação de livros tem uma importância desproporcional em diferentes disciplinas: ela é menos significativa na economia e na psicologia, onde a internacionalização acontece pela elaboração de artigos diretamente em inglês, assim como nas ciências naturais, e é muito mais significativa nas humanidades (nos estudos literários, na filosofia, na história). A antropologia e a sociologia estão situadas entre as duas. Mas o que interessa aqui é menos a proporção de livros traduzidos por disciplina do que as relações de poder entre as tradições nacionais, nas quais a linguagem atua como representante.

Como vimos, nessa segunda fase de institucionalização das ciências sociais, as editoras comerciais na França e em outros lugares publicaram séries específicas dedicadas às "ciências humanas". As traduções foram uma maneira de acumular capital simbólico durante esse período. Por outro lado, as traduções participaram da construção de um cânone internacional para as ciências sociais. Destacarei, a seguir, o mercado francês de livros acadêmicos.

As traduções corresponderam a dois terços dos 24 títulos lançados de 1950 a 1978 pela série "Bibliothèque de Philosophie" editada por Sartre e Merleau-Ponty (a maioria dos títulos provenientes do alemão, em particular, Heidegger, com duas exceções: Antonio Gramsci e o polonês Leszek Kołakowski). Em contraste com esse exemplo, as traduções foram menos presentes na história, a mais antiga e mais bem estabelecida disciplina, onde a produção doméstica foi significativa: as traduções corresponderam a menos de 30\% da "Bibliothèque des Histoires", da Gallimard. Quanto à sociologia e à antropologia, a metade das obras publicadas pela "Bibliothèque de Sciences Humaines" da Gallimard, até 1978 era composta por traduções: a antropologia anglo-americana estava bem representada por Elkin, Evans-Pritchard e Sahlins. O único título de sociologia era o de Veblen, introduzido por Raymond Aron. Mas a Gallimard também lançou em 1971 um livro de Paul Lazarsfeld intitula- 
do Qu'est-ce que la sociologie? em sua série de bolso "Idées". Na série de Bourdieu, "Le Sens Commun", publicada pelas Éditions de Minuit, a metade dos 63 títulos lançados entre o seu início, em 1966, e 1978 era de traduções (32 títulos), com 15 do inglês (principalmente de antropologia): Sapir, Linton, Radcliffe-Brow; sociologia: Goffman; sociolinguística: Bernstein e Labov; e estudos culturais: Hoggart, 12 do alemão (Cassirer, Panofsky, Marcuse, Adorno), quatro do grego antigo (Epicuro, Empédocles) e um do russo (Bakhtin/Voloshinov). Esse exemplo mostra que enquanto a tradição alemã dominou na filosofia (e também na história da arte), o conhecimento acadêmico anglo-americano estava se tornando uma referência central na antropologia e na sociologia.

Entretanto, a estratégia de Bourdieu foi a de contrabalançar o crescente predomínio do funcionalismo parsoniano e do positivismo quantitativo de Lazarsfeld na sociologia francesa do pós-guerra (ambos, introduzidos por Raymond Boudon) com a publicação de Goffman, um representante da corrente dominada nos Estados Unidos, de interacionismo simbólico, que desenvolveu métodos qualitativos de observação, entrevistas e análises de textos (Bourdieu, no entanto, iria publicar, em 1981, a pesquisa de Lazarsfeld, Les chômeurs de Marienthal). Ao mesmo tempo, Bourdieu publicou três volumes de obras de Mauss (1968) e três volumes com compilações de escritos de Durkheim (1975), todos editados por Victor Karady, reafirmando, assim, a tradição sociológica francesa perante a anglo-americana e contribuindo à canonização desses autores. De fato, entre 1963 e 1974, de acordo com o N-Gram Viewer, Parsons foi mais citado do que Durkheim em francês. Enquanto Parsons estabelecera sua legitimidade própria consolidando Durkheim e Weber como referenciais canônicos na disciplina, a sua ascensão a uma posição dominante no campo transnacional provavelmente contribuiu para a introdução de ambos no cânone sociológico mundial, até mesmo na França, onde a herança de Durkheim era contestada desde 1940 (Muel-Dreyfus, 2004), e onde Weber fora introduzido apenas de maneira marginal por Raymond Aron até o surgimento de sua primeira tradução, em 1959 (dois anos após a indicação de Aron a professor de sociologia na Sorbonne), desafiando assim a posição dominante de Gurvitch, que rejeitava a obra de Weber (Pollak, 1988). A maior parte da obra de Weber viria a ser traduzida entre 1959 e 1971.

Um sinal da canonização desses autores como clássicos foi a disputa que se iniciou durante o mesmo período em torno de sua apropriação entre uma nova geração de sociólogos, principalmente Pierre Bourdieu e Raymond Boudon, que os interpretavam de maneiras diferentes em apoio às suas próprias abordagens teóricas: enquanto Boudon os utilizou contra o marxismo e o estruturalismo, Bourdieu buscou fazer uma síntese original dessas teorias. Na sociologia anglo-americana, o domínio 
de Parsons culminou por volta de 1970, com o maior número de citações em inglês sendo alcançado, segundo o N-Gram Viewer, em 1971. Em seguida, a curva de Parsons começou a declinar constantemente, até que ele foi ultrapassado em 1996 por Bourdieu, que na atualidade possivelmente já se juntou a Durkheim e Weber no cânone transnacional (quanto à circulação internacional da obra de Bourdieu traduzida, ver Sapiro \& Bustamante, 2009; acerca da recepção da Distinção nos Estados Unidos, ver Sapiro, 2013b).

\section{Conclusão}

A disciplina sociológica com a qual estamos hoje familiarizados é resultado da convergência de quatro processos distintos. Em primeiro lugar, resulta do surgimento, no final do século XIX, de um campo científico que se especializou em fatos sociais, definidos como objetos sui generis que diferenciam esse campo do direito, da filosofia, da psicologia e da biologia. Em segundo lugar, a disciplina sociológica resulta da institucionalização acadêmica da disciplina promovida por alguns de seus empreendedores, como Durkheim na França, ou Alfred Weber em Heidelberg; o seu empenho se beneficiou da concorrência internacional que promoveu a institucionalização acadêmica das ciências humanas e sociais em muitos países, seguindo o modelo de ensino e pesquisa da Universidade de Humboldt. Assim, o elemento nacional não precisa ser contraposto ao internacional: o nacional foi construído, em grande medida, internacionalmente, enquanto gerava caminhos separados de desenvolvimento para os campos sociológicos nacionalizados.

Se na primeira metade do século, o isomorfismo acadêmico foi uma consequência principalmente da concorrência internacional, que favorecia a imitação, após a Segunda Guerra Mundial, a Unesco desempenhou um papel de apoiar a criação de associações internacionais que, por sua vez, promoveram a circulação de normas profissionais em nível nacional. Trata-se do terceiro processo. Enquanto isso, fundações filantrópicas incentivaram o desenvolvimento da pesquisa empírica nas ciências humanas e sociais. Os campos sociológicos se desenvolveram como campos científicos em muitos países, como fica demonstrado pelo surgimento de periódicos e institutos de pesquisa, à diferença dos regimes comunistas e das ditaduras latino-americanas, onde o processo de institucionalização iniciado na década de 1930 (na Hungria, Polônia ou Brasil, por exemplo) foi interrompido e adiado até os anos 1980.

O quarto fator foi o surgimento de um mercado editorial especializado nas ciências sociais e humanidades, juntamente com o processo de traduções iniciado nas décadas de 1950 e 1960, em paralelo ao aumento no número de estudantes. Esse fator ajudou a consolidar um cânone transnacional para essas novas disciplinas, no 
qual predominam os autores alemães, franceses e anglo-americanos - os alemães e franceses na filosofia, os anglo-americanos e franceses (graças ao estruturalismo) na antropologia, e os três grupos na sociologia.

A dupla institucionalização da sociologia como disciplina acadêmica e campo científico gerou primeiramente uma polarização dos campos sociológicos nacionais entre a teoria, que prevaleceu na academia, e a pesquisa empírica, que se desenvolveu em instituições de pesquisa.

Se, por um lado, a teoria circula mais facilmente, embora encontre uma concorrência intensa no mercado transnacional, em termos de comentários dos autores clássicos, por outro, a pesquisa empírica, que havia sido incentivada pelas fundações filantrópicas e dedicou-se mais à análise da dimensão internacional, tendeu, desde a década de 1970, a enfocar os contextos nacionais. Criada como disciplina internacional, a sociologia é atualmente uma das disciplinas mais nacionais em seus objetos, como consequência de diversos motivos relacionados à demanda, à acessibilidade ao trabalho de campo, e a financiamentos. Apesar disso, a oposição entre teoria e pesquisa empírica, e entre academia e instituições de pesquisa, não se sobrepõe à distinção entre orientação nacional e internacional, que é característica de todos os campos acadêmicos (Bourdieu, 1984). Entender como essa distinção atua requereria uma abordagem diferente, capaz de comparar a organização e as relações de poder dentro de cada campo nacional.

Além disso, a distinção entre nacional e internacional deve considerar hoje um processo de regionalização que se iniciou na década de 1950, com a fundação da Asociación Latinoamericana de Sociología e foi promovida, nos anos 1990, pela organização de um espaço europeu de pesquisas. Johan Heilbron (2014) descreve o campo global emergente da ciência social como uma estrutura centro-periferia com um núcleo duopolístico euramericano, muitas semiperiferias e um amplo leque de periferias, mas ressalta o fenômeno de regionalização. Essa regionalização está hoje organizada por órgãos regionais que encorajam a colaboração intrarregional, como o Conselho Latino-Americano de Ciências Sociais (Clacso), fundado em 1967, a Associação de Conselhos Asiáticos de Pesquisa em Ciência Social (Aassrec) e o Conselho para o Desenvolvimento da Pesquisa em Ciência Social na África (Codesria), fundados em 1973, e o Conselho Árabe para as Ciências Sociais (ACSS), criado em 2010 (para o caso europeu, ver Heilbron, Boncourt \& Timans, 2017; Heilbron, Boncourt, Schögler \& Sapiro, 2017).

Desde a década de 1980, o modelo de disciplinas acadêmicas tem sido desafiado pela reconfiguração da divisão do conhecimento, por um lado, com o aparecimento 
do modelo interdisciplinar dos "estudos": estudos de área, teatro, cinema, estudos de gênero, meio ambiente. O aparecimento desse modelo está relacionado a outro processo, que é a expansão da formação profissionalizante dentro das universidades - por exemplo, a administração é a disciplina que mais cresceu desde meados da década de 1980, na França. A sociologia tem sido um campo de conhecimento especializado para o planejamento estatal e para organizações corporativas, mas foi substituída, desde os anos 1980, pela economia e a administração. A sociologia foi útil para que os governos pensassem a respeito da modernização ou democratização da educação e da cultura no Estado do bem-estar social, mas hoje a administração se tornou a referência no contexto de novas políticas de gestão pública. Por ser considerada excessivamente crítica, a sociologia corre o risco de tornar-se uma disciplina ameaçada nos próximos anos - e isto, não apenas em regimes autoritários como o da Turquia.

\section{Referências}

ABBOTT, Andrew. Chaos of disciplines. Chicago (IL): The University of Chicago Press, 2001.

- The system of professions: an essay on the division of expert labor. Chicago (IL): The University of Chicago Press, 1988.

BARBANO, Filippo. La sociologia in Italia. Storia, temi e problemi (1945-1960). Roma: Carocci, 2012.

BERNARD, L. L. The teaching of sociology in the United States. American Journal of Sociology, v. 15, n. 2, p. 164-213, 1909.

BLUM, Alain. Les statisticiens et le stalinisme. In: HEILBRON, J.; LENOIR, R.; SAPIRO, G. (Eds.). Pour une histoire de sciences sociales. Hommage à Pierre Bourdieu, p. 245-262. Paris: Fayard, 2004.

BONCOURT, Thibaud. The struggles for European science. A comparative perspective on the history of European social science associations. Serendipities. Journal for the Sociology and History of the Social Sciences, v. 2, n. 1, p. 10-32, 2017.

- L'internationalisation de la science politique: une comparaison franco-btitannique (1945-2010). Bordeaux (FR): Institut d'Études Politiques, 2011.

— . La science internationale comme ressource. Genèse et développement comparés des associations européennes de sciences sociales. Revue Française de Sociologie, v. 57, n. 3, p. 529-561, 2016. 
BOURDIEU, Pierre. Séminaires sur le concept de champ, 1972-1975. Actes de la Recherche en Sciences Sociales, n. 200, p. 4-37, 2013.

—. Homo Academicus. Paris: Minuit, 1984.

—. Le Sens pratique. Paris: Minuit, 1980a.

- Quelques propriétés des champs. In: BOURDIEU, Pierre. Questions de sociologie, p. 113-120. Paris: Minuit, 1980b.

CALHOUN, Craig (Ed.). Sociology in America. A history. Chicago: The University of Chicago Press, 2008.

CASANOVA, Pascale. La République mondiale des lettres. Paris: Les Éditions du Seuil, 1999.

CHARLE, Christophe. La République des Universitaires (1870-1940). Paris: Les Éditions du Seuil, 1996.

COLLINS, Randall. The sociology of philosophies. A global theory of intellectual change. Cambridge (MA): Belknap Press, 1998.

COLLINS, Randall; BEN-DAVID, Joseph. Social factors in the origins of a new science: the case of psychology. American Sociological Review, v. 31, n. 4, p. 451-465, Aug. 1966.

DE SWAAN, Abram. Words of the world: the global language system. London: Polity, 2001.

DI MAGGIO, Paul; POWELL, Walter. The iron cage revisited: institutional isomorphism and collective rationality in organizational fields. American Sociological Review, v. 48, n. 2, p. 147-160, 1983.

FABIANI, Jean-Louis. Les philosophes de la République. Paris: Minuit, 1988.

FLECK, Christian. Sociology in Austria since 1945. Basingstoke (UK): Palgrave Macmillan, 2016.

- A transatlantic history of the social sciences: Robber Barons, the Third Reich and the invention of empirical social research. New York: Bloomsbury Academic, 2011.

FLECK, Christian; HEILBRON, Johan; KARADY, Victor; SAPIRO, Gisèle. Handbook of indicators of institutionalization of academic disciplines in $\mathrm{SSH}$. Serendipities Journal for the Sociology and History of the Social Sciences, v. 1, 2016 [on line]. 
FOUCAULT, Michel. Qu'est-ce qu'un auteur? In: FOUCAULT, Michel. Dits et écrits, t. I, 1954-1988, p. 789-820. Paris: Gallimard, 1994 [1969].

GARCIA, Afranio. A dependência da política. Fernando Henrique Cardoso e a sociologia no Brasil. Tempo Social, v. 16, n. 1, p. 285-300, 2004.

GINGRAS, Yves. Les formes spécifiques de l'internationalité du champ scientifique. Actes de la Recherche en Sciences Sociales, v. 141-142, p. 31-45, 2002.

HABERMAS, Jürgen. Logiques des sciences sociales. In: HABERMAS, Jürgen. Logiques des sciences sociales et autres essais p. 1-238. Paris: Presses Universitaires de France, 1987 [1967].

HEILBRON, Johan. French sociology. Ithaca (NY); London: Cornell University Press, 2015.

. The social sciences as an emerging global field. Current Sociology, v. 62, n. 5, p. 685-703, 2014.

HEILBRON, Johan; LENOIR, Rémi; SAPIRO, Gisèle (Eds.). Pour une histoire de sciences sociales. Hommage à Pierre Bourdieu. Paris: Fayard, 2004.

HEILBRON, Johan; JEANPIERRE, Laurent; GUILHOT, Nicolas. Vers une histoire transnationale des sciences sociales. Sociétés Contemporaines, v. 73, n. 1, p. 121145, 2009.

HEILBRON, Johan; BONCOURT, Thibaud; TIMANS, Rob (Eds.). The social sciences and humanities in the european research area. Serendipities. Journal for the Sociology and History of the Social Sciences, v. 2, n. 1, 2017 [on line].

HEILBRON, Johan; BONCOURT, Thibaud; SCHÖGLER, Rafael; SAPIRO, Gisèle. European social sciences and humanities (SSH) in a global context preliminary findings from the Interco-ssh Project, 2017a. Disponível em: <http://interco-ssh.eu/working-papers/>.

HEILBRON, Johan; BONCOURT, Thibaud; SAPIRO, Gisèle; SORÁ, Gustavo; KARADY, Victor; BRISSON, Thomas; JEANPIERRE, Laurent; LEE, Kil-Ho. Indicators of the internationalization of the social sciences and humanities. Serendipities. Journal for the Sociology and History of the Social Sciences, v. 2, 2017b [on line].

HENRY, Odile. Les guérisseurs de l'économie. Sociogenèse du métier de consultant (1900-1944). Paris: CNRS Éditions, 2012. 
HOUDEVILLE, Gérard. Le métier de sociologue en France depuis 1945. Rennes (FR): Presses universitaires de Rennes, 2007.

JEANPIERRE, Laurent. Des hommes entre plusieurs mondes. Étude sur une situation d'exil: intellectuels français réfugiés aux Etats-Unis pendant la deuxième guerre Mondiale. Thèse (Doctorat en Sociologie) - École des Hautes Études en Sciences Sociales (Ehess), Paris, França, 2004.

JOLY, Marc. La révolution sociologique. De la naissance d'un régime de pensée scientifique à la crise de la philosohpie (XIX-XXe siècle). Paris: La Découverte, 2017.

JOSEPH, Camille. Les éditions La Découverte: la gestion d'un héritage éditorial. Thèse (Doctorat en Sociologie) - École des Hautes Études en Sciences Sociales (Ehess), Paris, França, 2010.

KARADY Victor. L'émergence d'un espace européen des connaissances sur l'homme en société: cadres institutionnels et démographiques. In: SAPIRO, Gisèle (Ed.). L'Espace intellectuel en Europe. De la formation des États-nations à la mondialisation XIXe-XXIe siècle, p. 43-67. Paris: La Découverte, 2009.

— Durkheim, les sciences sociales et l'université: bilan d'un semi-échec. Revue Française de Sociologie, v. 17, p. 267-311, 1976.

KÄSLER, Dirk. Die frühe deutsche Soziologie 1909 bis 1934 und ihre Entstehungs-Milieus. Eine wissenschaftssoziologische UntersuchungProgramm Einer Wissenschaftssoziologischen Analyse der Entstehung und Entwicklung der Frühen Deutschen Soziologie 1909-1934. Wiesbaden: Verlag Fur Sozialwissenschaften, 2013.

KUHN, Thomas, S. La structure des révolutions scientifiques. 2. ed. Paris: Flammarion, 1970.

LEPSIUS, m. r. the development of sociology in germany after world war ii (19451968). international sociology, v. 13, p. 3-88, 1983.

. 2. ed. São Paulo,

LOYER, Emmanuelle. Paris à New York. Intellectuels et artistes français en exil, 19401947. Paris: Grasset, 2005.

MUEL-DREYFUS, Francine. La rééducation de la sociologie sous le régime de Vichy. Actes de la Recherche en Sciences Sociales, v. 153, n. 3, p. 65-77, 2004.

PLATT, Jennifer. The British Sociological Association: a sociological history. London: Routledge, 2003. 
POLLAK, Michael. La place de Max Weber dans le champ intellectuel français. Droit et Société, v. 9, p. 189-201, 1988.

- La planification des sciences sociales. Actes de la Recherche en Sciences Sociales, v. 2, n. 2-3, p. 105-121, 1976.

PRÉVOST, Jean-Guy. A total science: statistics in liberal and fascist Italy. Montréal; Kingston: McGill; Queen's University Press, 2009.

RAMSTEDT, Otto. Deutsche Soziologie 1933-1945. Die Normalität einer Anpassung. Berlin: Suhrkamp, 1986.

SAPIRO, Gisèle. How do literary texts cross borders (or not). Journal of World Literature, v. 1, n. 1, p. 81-96, 2016.

- Le champ est-il national? La théorie de la différenciation sociale au prisme de l'histoire globale. Actes de la Recherche en Sciences Sociales, n. 200, p. 70-85, 2013a.

- La carrière internationale de La Distinction. In: COULANGEON, Philippe; DUVAL, Julien (Dirs.). Trente ans après La Distinction de Pierre Bourdieu, p. 45-58. Paris: La Découverte, 2013b.

SAPIRO, Gisèle; BUSTAMANTE, Mauricio. Translation as a measure of international consecration. Mapping the world distribution of Bourdieu's books in translation. Sociologica, n. 2-3, 2009 [on line].

SAPIRO, Gisèle; BRUN, Eric, FORDANT, Clarisse. The rise of the social sciences and humanities in France: institutionalization, professionalization and autonomization. In: FLECK, C.; KARADY, V.; DULLER, M. (Eds.). Institutionalization of the social sciences and humanities in Europe and beyond, Basingstock (UK): Palgrave McMillan [in press].

STEINMETZ, George (Ed.). Sociology and empire: the imperial entanglements of a discipline. Durham (UK): Duke University Press, 2013.

. La sociologie et l'empire: Richard Thurnwald et la question de l'autonomie scientifique. Actes de la Recherche en Sciences Sociales, n. 185, p. 12-29, 2010.

- The historical sociology of historical sociology. Germany and the United States in the Twentieth Century. Sociologica, v. 3, 2007 [on line].

- American sociology before and after World War Two: the (temporary) settling of a disciplinary field. In: CALHOUN, C. (Ed.). Sociology in America. a history, p. 258-293. Chicago (IL): University of Chicago Press, 2006. 
STICHWEH, Rudolf. The sociology of scientific disciplines. On the genesis and stability of the disciplinary structure of modern science. Science in Context, v. 5, n. 1, p. 3-15, 1992.

TESNIÈRE, Valérie. Le Quadrige. Un siècle d'édition universitaire 1860-1968. Paris: Presses Universitaires de France, 2001.

THIESSE, Anne-Marie. La création des identités nationales. Europe XVIII-XXe siècles. Paris: Les Éditions du Seuil, 1998.

WALLERSTEIN, Immanuel. World-systems analysis: an introduction. Durham (UK): Duke University Press, 2004.

WERNER, Michael; ZIMMERMANN, Bénédicte. Beyond comparison: histoire croisée and the challenge of reflexivity. History and Theory, v. 45, p. 30-50, 2006.

WIMMER, Andreas; SCHILLER, Nina Glick. Methodological nationalism, the social sciences, and the study of migration: an essay in historical epistemology. The International Migration Review, v. 37, n. 3), p. 576-610, 2003. 